\title{
Synthesis and Human Telomerase Inhibition of a Series of Regioisomeric Disubstituted Amidoanthraquinones
}

\author{
Hsu-Shan Huang, ${ }^{*, a}$ In-Been Chen, ${ }^{a}$ Kuo-Feng Huang, ${ }^{b}$ Wei-Chih Lu, ${ }^{c}$ Fu-Ying ShIEH, ${ }^{d}$ \\ Yi-Yuan Huang, ${ }^{d}$ Fong-Chun HuAng, ${ }^{d}$ and Jing-Jer LiN ${ }^{*}, d$ \\ ${ }^{a}$ School of Pharmacy, National Defense Medical Center; Taipei 114, Taiwan: ${ }^{b}$ Chi-Mei Medical Center; Tainan 710, \\ Taiwan: ${ }^{c}$ Cheng-Hsin Medical Center; Taipei 112, Taiwan: and ${ }^{d}$ Institute of Biopharmaceutical Science, National Yang- \\ Ming University; Taipei 112, Taiwan, R.O.C. Received September 28, 2006; accepted November 16, 2006
}

Telomerase is the enzymatic activity that maintains the ends of eukaryotic chromosomes. Telomerase activity is detected in most tumor cells whereas it is low or undetectable in most normal somatic cells. Expression of the telomerase catalytic component, the human telomerase reverse transcriptase (hTERT), is believed to be controlled primarily at the level of transcription. Because of this selective expression property of telomerase, it has been touted as a specific target for antitumor chemotherapeutics. However, a concern for the applicability of telomerase inhibitors is that they require a long lag time for telomeres to be shortened to critical length before cancer cells stop proliferating. Here we investigate telomerase inhibitory, cytotoxicity and the hTERT repressing effects on a number of synthesized 2,6-diamidoanthraquinones and 1,5-diamidoanthraquinones as compared to their disubstituted homologues. We found that several of the 1,5-diamidoanthraquinones and 2,6-diamidoanthraquinones inhibited telomerase activity effectively with $\mathrm{IC}_{50}$ at the sub-micro to micro molar range and caused acute cytotoxicity to cancer cells with $\mathrm{EC}_{50}$ similar or better than that of mitoxantrone. Particularly, 2,6diamidoanthraquinone with 2-ethylaminoacetamido side chains 33, even though not affecting cell proliferation, showed to be endowed with a strong telomerase effect, probably related to a marked stabilization of the Gquadruplex-binding structure. The results suggested that these compounds caused multiple effects to cancer cells. More significantly, they overcome the long lag period problem of classical telomerase inhibitors that they are also potent cytotoxic agents. These results greatly expand the potential of tricyclic anthraquinone pharmacophore in preventive and/or curative therapy.

Key words telomerase inhibition; cytotoxicity; anthraquinone; human telomerase reverse transcriptase (hTERT); G-quadruplex; secreted alkaline phosphatase (SEAP) assay; telomerase assay; TRAP assay

Most human somatic cells divide 50-60 times before senescence occurs. These cells invariably enter a state of irreversibly arrested growth. This process, termed replicative senescence, is thought to be a tumor-suppressive mechanism and an underlying cause of aging. ${ }^{1)}$ The molecular mechanism underlying cellular senescence has been characterized. It is well accepted that telomeres play a major role in the process. Telomeres are the physical ends of linear eukaryotic chromosomes. They consist of hundreds to thousands of tandem repeats of the sequence TTAGGG, that are essential for stabilizing chromosomes. ${ }^{2)}$ Because conventional DNA polymerase cannot replicate the very end of chromosomes, telomere length is shortened upon each DNA replication. Telomerase is the enzyme activity that elongates short telomeres. Because telomerase activity is low or not detectable in most normal human somatic cells, telomeric DNA is progressively shortened with each cell division. The shortened telomeres then signal cells to enter senescence through a DNA damage signaling pathway. Telomere length is considered as a biological clock that is capable of determining the proliferative capacity of most human somatic cells. ${ }^{3,4)}$

While telomerase is not detected or is low in most of the normal human cells, it is detected in $c a$. $85-90 \%$ of the immortalized or tumor cells. In humans, telomerase activity is tightly regulated by expression of the human telomerase reverse transcriptase (hTERT) gene, which appears to be the key regulator for telomerase activity. Inhibition or activation of the hTERT expression could profoundly affect the proliferative capacity of normal cells and cancers. ${ }^{5-7)}$ Because telomerase is required for the sustained proliferation of most immortal cells, including cancer cells, it has become the focus of much attention as a novel and potentially highlyspecific target for the development of new anticancer chemotherapeutics. In this respect, antisense oligonucleotides or small molecular inhibitors have been identified as inhibitors to telomerase. ${ }^{8)}$ Several of them effectively inhibit telomerase in vitro and limit the proliferation of cancer cells in vivo. ${ }^{9)}$ However, because a lag period is required for telomeres to be shortened to critical short length, the clinical applicability of telomerase inhibitor was questioned. For example, it takes $c a .20$ additional cell divisions for telomeres of HeLa cells to be shortened to critical length. ${ }^{8)}$ It is not realistic for telomerase inhibitor to be used in treating cancers. Thus, it was proposed that telomerase inhibitors should work with other chemotherapeutic agents for treating cancers. ${ }^{10)}$ The use of cytotoxic agents to kill cancer cells and telomerase inhibitor to limit the proliferative potential of residual cancer cells should be a better approach in cancer chemotherapy. Interestingly, guanine-quadruplex (G-quadruplex) stabilizers such as 2,6-pyridine-dicarboxamide derivatives and 3,6,9-trisubstituted acridine compounds caused accelerated senescence in cancer cells. Molecules able to stabilize the G-quadruplex (G4), a structure adopted by the $3^{\prime}$ overhang of telomeres, are thought to inhibit telomerase by blocking its access to telomeres. ${ }^{112)}$ Thus, the phenotypical lag for typical telomerase inhibitors could be by-passed by these types of compounds.

In a continuation of our work on anthraquinones that widely occur in the plant kingdom and anthraquinone-based compounds currently occupy a prominent position in anti- 


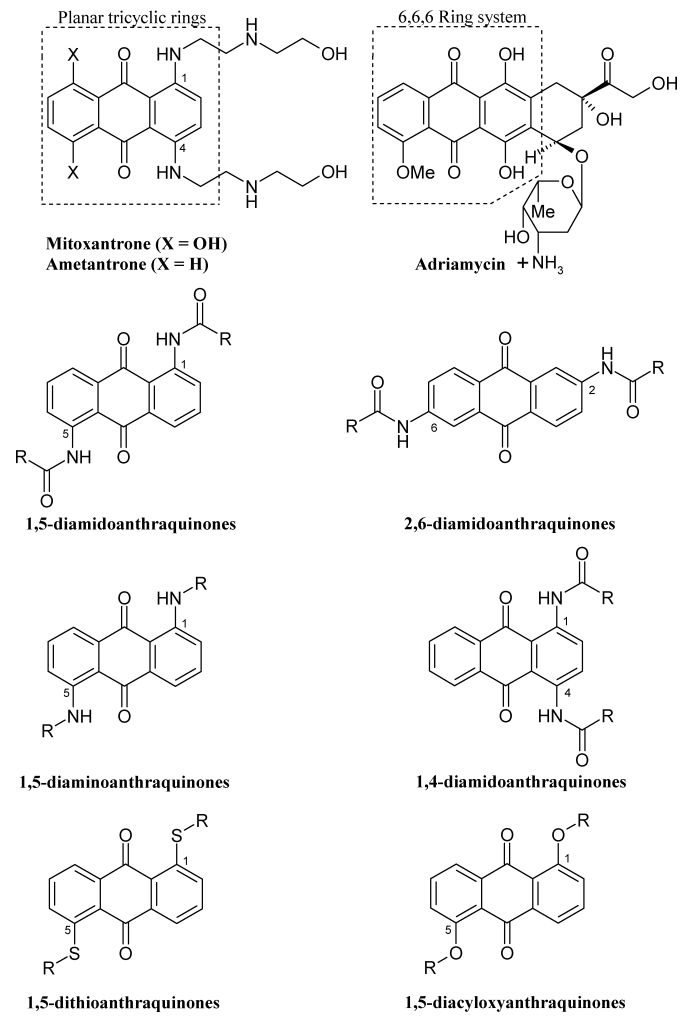

Chart 1

cancer drugs development. Mitoxantrone and ametantrone are antitumor 1,4-bis[(aminoalkyl)amino]anthraquinones that were discovered by molecular simplification of the anthracycline pharmacophore. ${ }^{13-15)}$ However, adriamycin (doxorubicin, Chart 1) has structural characteristics that limit its efficacy and safety. New anthracyclines with distinct structure, pharmacokinetics, pharmacodynamics, and toxicity profiles have been developed to overcome the limitations of doxorubicin and to further exploit the activity of anthracyclines. ${ }^{16)}$ Although the reaction mechanism of the antitumor activity of anthraquinone is probably multimodal in nature, a number of studies have indicated that its interaction with DNA may play a major role. ${ }^{17-19)}$ Through stabilizing G-quadruplex complexes formed by telomeric DNA sequences, it has been shown that several 1,4-disubstituted amidoanthraquinones, and some 1,4- and 1,5-disubstituted aminoanthraquinones inhibited telomerase activity. ${ }^{20-26)}$ Anthraquinones could also modulate hTERT expression. Using a reporter system, our previous studies indicated that several of the symmetrically disubstituted 1,5-diacyloxyanthraquinones activate hTERT expression. ${ }^{27)}$ These results provide a new clue on the effects of the anthraquinone compounds on modulation of hTERT gene expression.

The study of molecules structurally related to antitumor anthraquinone is expected to provide useful information in the biological activity and a rational basis for further analogue development. The present study explores the effects on cytotoxicity, telomerase inhibitory, and hTERT expression using cell-based assay systems with two distinct series of amidoanthraquinones substituted at the 1,5-, and 2,6-positions as compare to their homologues. A range of side chains has been examined to establish structure-activity relationships (SARs) as a basis for subsequent rational drug design.

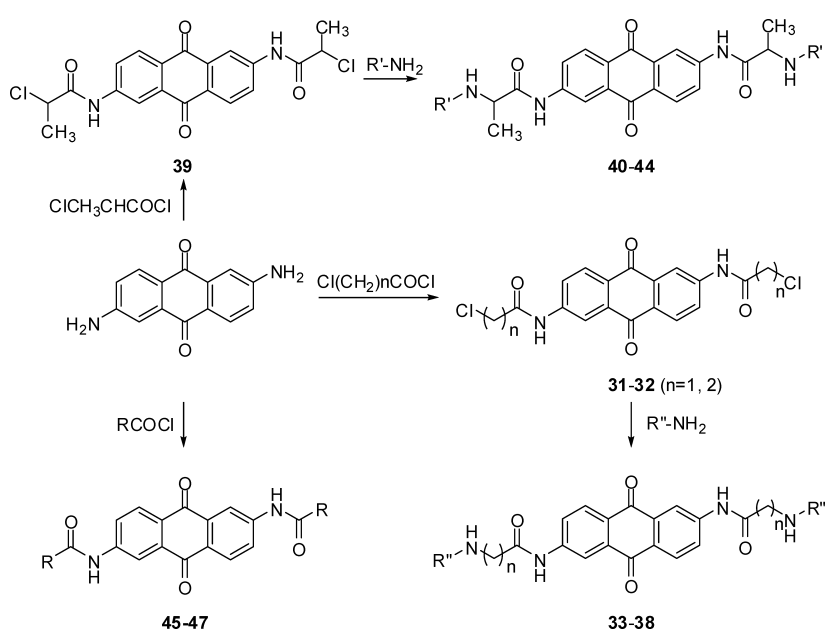

Chart 2

We have identified these anthraquinones that inhibit telomerase and cytotoxic effects. Significantly, several of the most potent cytotoxic anthraquinones process potent telomerase inhibitory activities. These compounds have potential in future anticancer drug developments that not only cause cytotoxic effects but also inhibit telomerase activity in cancer cells.

\section{Chemistry}

The general synthetic approach for the 2,6-disubstituted amidoanthraquinones is shown in Chart 2. Starting material 2,6-diaminoanthraquinone was first acylated with acyl chlorides in $N, N$-dimethylacetamide with a catalytic quantity of pyridine and subsequently reacted with appropriate amines in DMSO to obtain the desired compounds. Here the reactions of electrophilic additions/substitutions and nucleophilic additions occurred at different position states of anthraquinones. These compounds were obtained in good yields and their purity was determined using mass spectrometry, ${ }^{1} \mathrm{H}$ - and ${ }^{13} \mathrm{C}$ NMR.

\section{Biological Activity and Discussion}

It was shown that some of disubstituted anthraquinones inhibit telomerase, affect cell growth, and modulate hTERT expression. ${ }^{23,25,28,29)}$ By comparing these results with our compounds, ${ }^{20,27,30,31)}$ it is clear that the chemical and biological activities of anthraquinones are greatly affected by various substituents of the planar ring system. ${ }^{17,22,25,29,32-36)}$ Neidle $e t$ $a l^{23,25,28,29)}$ have also indicated that some of disubstituted anthraquinones inhibit telomerase which provide us rational design for the further investigation of SARs and comparison with their series of disubstituted homologues. Previously we described a method of synthesizing 1,5-diamidoanthraquinones (2-17) and comparing to their cytotoxicity, ${ }^{31)}$ these compounds considered as aglycon analogues of anthracycline antibiotics in which the side chains substitutes for small-molecule planar tricyclic anthraquinone structural motifs. In this investigation, we continue to focus our attention on the role of our newly synthesized 2,6-diamidoanthraquinones. In addition, the analysis is further extended to the potential functions of anthraquinones with substitutions on the different positions. The backbone of these compounds 
also resemble the anticancer agents mitoxantrone and ametantrone, and were prepared by a two-stage reaction which similar to our previous paper. ${ }^{30,31)}$ We first evaluate the effects of these disubstituted amidoanthraquinones on telomerase activity using PCR-based telomerase assay, and TRAP (telomeric repeat amplification protocol) assay. Here, a modified telomerase assay (TRAP-G4) is used to evaluate the effects of anthraquinones on G-quadruplex-induced telomerase activity. ${ }^{37)}$ In the TRAP-G4 assay, a G-quadruplex sequence was introduced into the telomerase extension primer that is susceptible to forming an intramolecular G-quadruplex. Because the formation of G-quadruplex blocks telomerase extension, this TRAP-G4 assay enables the evaluating the effects of G-quadruplex stabilizing agents on telomerase activity. The inhibitory effect of anthraquinones at $15-30 \mu \mathrm{M}$ concentrations was tested. Among a total of 1,5-diamidoanthraquinones and 2,6-diamidoanthraquinones were tested, we found that 1,5-diamidoanthraquinones 5, 17, and 2,6-diamidoanthraquinones $\mathbf{3 3}$ and $\mathbf{3 4}$ showed telomerase inhibitory effect at the concentrations of 0.1 and $5.0 \mu \mathrm{M}$. The 1,5-diamidoanthraquinones with side chains $\mathrm{CH}_{2} \mathrm{NHCH}_{2} \mathrm{CH}_{3} 5$ and $(\mathrm{CH}) \mathrm{CH}_{3} \mathrm{NH}\left(\mathrm{CH}_{2}\right)_{3} \mathrm{~N}\left(\mathrm{CH}_{3}\right)_{2}$ 17, show inhibition of Gquadruplex-induced telomerase at the $\mathrm{IC}_{50}$ levels of 5.0 and $2.0 \mu \mathrm{M}$, respectively, whereas 2,6-diamidoanthraquinones with side chains $\mathrm{CH}_{2} \mathrm{NHCH}_{2} \mathrm{CH}_{3} 33$ and $\mathrm{CH}_{2} \mathrm{NH}\left(\mathrm{CH}_{2}\right)_{2} \mathrm{CH}_{3}$ 34, show $\mathrm{IC}_{50}$ levels of 0.1 and $2.0 \mu \mathrm{M}$, respectively. The inhibitory effects of these compounds on telomerase are specific as they did not affect the internal controls (ICs) for Taq polymerase in our assays. These compounds are the most potent telomerase inhibitors in this series of compounds. Interestingly, most of 1,5-dithioanthraquinones and 1,5-diacyloxyanthraquinones did not affect telomerase activity, on the contrary 1,5-diacyloxyanthraquinones with side chains $-\mathrm{COCH}_{2} \mathrm{CH}_{3},-\mathrm{COC}\left(\mathrm{CH}_{3}\right)_{3}$ and $-\mathrm{COC}_{6} \mathrm{H}_{3} \mathrm{Cl}_{2}(o, p)$ activate hTERT expression in normal cells. ${ }^{27)}$ Thus, in addition to anticancer functions, our finding raises the possibility that these compounds might have potential application for cell immortalization.

The analysis systems used cell lines derived from H1299 (non-small cell lung cancer cells) and hTERT-BJ1 (human normal skin fibroblast cells immortalized with hTERT gene) cells. These cells were generated by introducing H1299 or hTERT-BJ1 cells with DNA constructs harboring $\mathrm{P}_{\mathrm{hTERT}^{-}}$ SEAP (secreted alkaline phosphatase), so that the $3.4 \mathrm{kbp}$ hTERT promoter fused upstream to a reporter gene, SEAP. Thus, the expression of SEAP in H1299 cells harboring $\mathrm{P}_{\text {hTERT }}$-SEAP could be used as the criteria to evaluate if anthraquinone derivatives inhibited the expression of hTERT in cancer cells. Similarly, the activation of hTERT expressions could be monitored by the SEAP expressions using hTERTBJ1 cells. The levels of cell viabilities in these cells upon drug treatments were also determined using MTT assay. We showed that mitoxantrone gave an $\mathrm{EC}_{50}$ of $c a .20 \mu \mathrm{M}$ under our assay conditions. Our results indicated that the 1,5-diamidoanthraquinone compounds 5, 8, 12, 15, and 20 showed $\mathrm{EC}_{50}<2 \mu \mathrm{M}$, that is more than 10 fold effective than that by mitoxantrone. In contrast, most of the 2,6-diamidoanthraquinones did not show significant cytotoxic activity, only compounds 33 and 34 showed $\mathrm{EC}_{50}$ values similar to or a little better than mitoxantrone. Thus, it appears that diamido substitutions at 2,6-positions of anthraquinones are not cru-
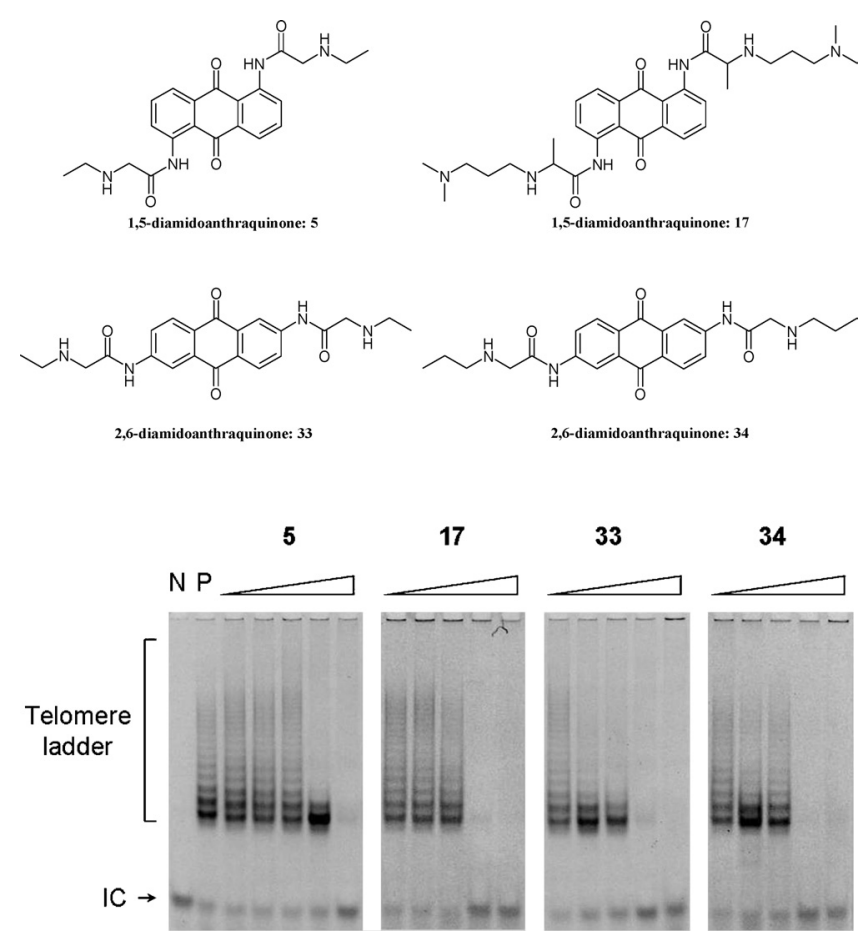

Chart 3. Inhibition of Telomerase Activity by Disubstituted Amidoanthraquinones

TRAP-G4 assay was conducted using cell extracts prepared from H1299 cells and $2 \mu \mathrm{g}$ of extracts were used in each assay. Extended products were separated on a $10 \%$ polyacrylamide gel and visualized with SYBER Green staining. The photo pictures of the results are presented. The concentration of test compounds were $0.001,0.01,0.1,1$, $10 \mu \mathrm{M}$, respectively. Because the internal control (IC) shares one oligonucleotide with the reaction, the IC products became apparent when telomerase activities were inhibited. $\mathrm{P}$ is positive control and $\mathrm{N}$ is negative control.

\section{cial for the cytotoxic effects.}

The mechanism of mitoxantrone action is cell cycle-independent that it kills both proliferating and non-proliferating cells. This property makes it different from many other cytotoxic agents. ${ }^{38)}$ By comparing the telomerase inhibitory of 1,5-diamido-, 2,6-diamido-, 1,5-diamino-, and 1,4-diamidodisubstituted anthraquinones in Table 2, it appears that on each position the bulkier or similar to the substituent of mitoxantrone, the higher the activity.

Previously we have identified several 1,5-diacyloxy-, 1,5dithio-, and 1,4-diamidoanthraquinones that activated the SEAP expression in hTERT-BJ1 cells. To our surprise, none of the 1,5-diamido and 2,6-diamidoanthraquinones affect hTERT expression in hTERT-BJ1 and H1299 cells. Thus, our results indicate that diamido substitution at 2,6 positions of anthraquinones were not capable of affecting hTERT expression. Moreover, while substitution at 1,5 positions are important for activating hTERT expression, amido group might not be the choice for future design of these types of compounds. Our finding provided a new clue on future design of compounds for potential application in cell immortalization.

\section{Conclusions}

Anthraquinone-base molecules have been reported to bind the G-quadruplex DNA formed by telomeric DNA and inhibit telomerase activity. ${ }^{25,26,28,39,40)}$ Telomerase inhibitor causes the attrition of telomere length and consequently leading to senescence which require a lag period for cancer cells to stop proliferating. Such a mechanism and result, if it is to 
Table 1. Effects of Symmetrical Diamidoanthraquinones on Activating or Repressing hTERT Expression and Telomerase Activity

\begin{tabular}{|c|c|c|c|c|c|c|c|}
\hline \multirow[b]{2}{*}{ Compd. } & \multirow[b]{2}{*}{$\mathrm{R}$} & \multirow{2}{*}{$\begin{array}{l}\text { Concn. } \\
\left.(\mu \mathrm{M})^{a}\right)\end{array}$} & \multicolumn{2}{|c|}{$\mathrm{P}_{\mathrm{hTERT}}-\mathrm{SEAP}(\mathrm{hTERT}-\mathrm{BJ} 1)^{b)}$} & \multicolumn{2}{|c|}{$\mathrm{P}_{\mathrm{hTERT}}-\mathrm{SEAP}(\mathrm{H} 1299)^{c)}$} & \multirow{2}{*}{$\begin{array}{c}\text { TRAP assay } \mathrm{IC}_{50} \\
(\mu \mathrm{M})\end{array}$} \\
\hline & & & $\begin{array}{l}\text { Viability } \\
(\%)\end{array}$ & $\begin{array}{c}\text { Relative SEAP } \\
\text { activity (\%) }\end{array}$ & $\begin{array}{l}\text { Viability } \\
(\%)\end{array}$ & $\begin{array}{c}\text { Relative SEAP } \\
\text { activity (\%) }\end{array}$ & \\
\hline \multirow[t]{3}{*}{2} & $\mathrm{CH}_{2} \mathrm{Cl}$ & 2.6 & $63 \pm 8$ & $65 \pm 10$ & $68 \pm 4$ & $61 \pm 5$ & $>25.6$ \\
\hline & & 25.6 & $38 \pm 7$ & $23 \pm 6$ & $34 \pm 2$ & $31 \pm 5$ & \\
\hline & & 256 & $8 \pm 8$ & $8 \pm 2$ & $14 \pm 2$ & $18 \pm 10$ & \\
\hline \multirow[t]{3}{*}{3} & $\left(\mathrm{CH}_{2}\right)_{2} \mathrm{Cl}$ & 2.4 & $83 \pm 11$ & $84 \pm 10$ & $76 \pm 13$ & $89 \pm 12$ & $>23.9$ \\
\hline & & 23.9 & $84 \pm 8$ & $72 \pm 11$ & $47 \pm 11$ & $32 \pm 6$ & \\
\hline & & 239 & $16 \pm 2$ & $16 \pm 12$ & $12 \pm 2$ & $21 \pm 7$ & \\
\hline \multirow[t]{3}{*}{4} & $\left(\mathrm{CH}_{2}\right)_{3} \mathrm{Cl}$ & 2.2 & $80 \pm 3$ & $76 \pm 3$ & $75 \pm 5$ & $72 \pm 6$ & $>22.4$ \\
\hline & & 22.4 & $47 \pm 5$ & $43 \pm 6$ & $53 \pm 4$ & $55 \pm 6$ & \\
\hline & & 224 & $13 \pm 4$ & $9 \pm 5$ & $10 \pm 2$ & $9 \pm 5$ & \\
\hline \multirow[t]{3}{*}{5} & $\mathrm{CH}_{2} \mathrm{NHCH}_{2} \mathrm{CH}_{3}$ & 2.4 & $28 \pm 5$ & $31 \pm 5$ & $30 \pm 5$ & $33 \pm 4$ & 5.0 \\
\hline & & 24.5 & $18 \pm 5$ & $20 \pm 5$ & $9 \pm 6$ & $12 \pm 7$ & \\
\hline & & 245 & $12 \pm 6$ & $11 \pm 7$ & $8 \pm 4$ & $6 \pm 5$ & \\
\hline \multirow[t]{3}{*}{6} & $\mathrm{CH}_{2} \mathrm{NH}\left(\mathrm{CH}_{2}\right)_{2} \mathrm{CH}_{3}$ & 2.3 & $68 \pm 7$ & $75 \pm 6$ & $91 \pm 8$ & $97 \pm 5$ & $>22.9$ \\
\hline & & 23 & $62 \pm 6$ & $61 \pm 8$ & $36 \pm 2$ & $37 \pm 4$ & \\
\hline & & 229 & $15 \pm 4$ & $16 \pm 3$ & $8 \pm 3$ & $4 \pm 4$ & \\
\hline \multirow[t]{3}{*}{7} & $\mathrm{CH}_{2} \mathrm{NH}\left(\mathrm{CH}_{2}\right)_{3} \mathrm{CH}_{3}$ & 2.2 & $77 \pm 6$ & $79 \pm 6$ & $70 \pm 3$ & $72 \pm 5$ & $>21.5$ \\
\hline & & 21.5 & $40 \pm 6$ & $39 \pm 8$ & $45 \pm 1$ & $35 \pm 6$ & \\
\hline & & 215 & $24 \pm 5$ & $26 \pm 7$ & $28 \pm 2$ & $20 \pm 3$ & \\
\hline \multirow[t]{3}{*}{8} & $\mathrm{CH}_{2} \mathrm{NH}\left(\mathrm{CH}_{2}\right)_{4} \mathrm{CH}_{3}$ & 2.0 & $32 \pm 9$ & $37 \pm 6$ & $29 \pm 1$ & $36 \pm 5$ & $>20.3$ \\
\hline & & 20 & $16 \pm 5$ & $12 \pm 4$ & $13 \pm 2$ & $12 \pm 4$ & \\
\hline & & 203 & $10 \pm 4$ & $6 \pm 6$ & $4 \pm 3$ & $3 \pm 3$ & \\
\hline \multirow[t]{3}{*}{9} & $\mathrm{CH}_{2} \mathrm{NH}\left(\mathrm{CH}_{2}\right)_{5} \mathrm{CH}_{3}$ & 1.9 & $83 \pm 6$ & $86 \pm 5$ & $95 \pm 2$ & $92 \pm 3$ & $>19.2$ \\
\hline & & 19.2 & $79 \pm 8$ & $89 \pm 5$ & $88 \pm 1$ & $90 \pm 4$ & \\
\hline & & 192 & $5 \pm 4$ & $6 \pm 4$ & $71 \pm 3$ & $69 \pm 1$ & \\
\hline \multirow[t]{3}{*}{10} & $\mathrm{CH}_{2} \mathrm{~N}\left(\mathrm{CH}_{2} \mathrm{CH}_{3}\right)_{2}$ & 2.2 & $70 \pm 6$ & $75 \pm 5$ & $75 \pm 4$ & $80 \pm 7$ & $>21.5$ \\
\hline & & 21.5 & $61 \pm 7$ & $63 \pm 6$ & $53 \pm 3$ & $59 \pm 4$ & \\
\hline & & 215 & $40 \pm 5$ & $38 \pm 4$ & $35 \pm 5$ & $31 \pm 2$ & \\
\hline 11 & $(\mathrm{CH}) \mathrm{CH}_{3} \mathrm{Cl}$ & 2.4 & $103 \pm 5$ & $96 \pm 6$ & $81 \pm 4$ & $88 \pm 4$ & $>23.9$ \\
\hline & & 23.9 & $76 \pm 8$ & $69 \pm 7$ & $70 \pm 4$ & $64 \pm 10$ & \\
\hline & & 239 & $31 \pm 2$ & $25 \pm 8$ & $24 \pm 2$ & $23 \pm 4$ & \\
\hline 12 & $(\mathrm{CH}) \mathrm{CH}_{3} \mathrm{NHCH}_{2} \mathrm{CH}_{3}$ & 2.3 & $43 \pm 5$ & $39 \pm 5$ & $21 \pm 5$ & $35 \pm 9$ & $>22.9$ \\
\hline & & 22.9 & $21 \pm 6$ & $19 \pm 7$ & $8 \pm 4$ & $9 \pm 9$ & \\
\hline & & 229 & $5 \pm 3$ & $3 \pm 4$ & $4 \pm 4$ & $4 \pm 5$ & \\
\hline 13 & $(\mathrm{CH}) \mathrm{CH}_{3} \mathrm{NH}\left(\mathrm{CH}_{2}\right)_{2} \mathrm{CH}_{3}$ & 2.2 & $80 \pm 9$ & $74 \pm 2$ & $100 \pm 11$ & $97 \pm 5$ & $>21.5$ \\
\hline & & 21.5 & $64 \pm 4$ & $64 \pm 2$ & $86 \pm 7$ & $80 \pm 7$ & \\
\hline & & 215 & $42 \pm 5$ & $38 \pm 2$ & $53 \pm 5$ & $61 \pm 10$ & \\
\hline 14 & $(\mathrm{CH}) \mathrm{CH}_{3} \mathrm{NH}\left(\mathrm{CH}_{2}\right)_{3} \mathrm{CH}_{3}$ & 2.0 & $64 \pm 8$ & $68 \pm 3$ & $73 \pm 8$ & $71 \pm 8$ & $>20.3$ \\
\hline & & 20.3 & $40 \pm 7$ & $33 \pm 2$ & $70 \pm 3$ & $64 \pm 9$ & \\
\hline & & 203 & $39 \pm 5$ & $41 \pm 1$ & $28 \pm 7$ & $20 \pm 10$ & \\
\hline 15 & $(\mathrm{CH}) \mathrm{CH}_{3} \mathrm{NH}\left(\mathrm{CH}_{2}\right)_{4} \mathrm{CH}_{3}$ & 1.9 & $55 \pm 9$ & $59 \pm 7$ & $49 \pm 4$ & $54 \pm 6$ & $>19.2$ \\
\hline & & 19.2 & $9 \pm 6$ & $15 \pm 5$ & $11 \pm 5$ & $10 \pm 1$ & \\
\hline & & 192 & $10 \pm 6$ & $13 \pm 6$ & $6 \pm 4$ & $7 \pm 1$ & \\
\hline 16 & $(\mathrm{CH}) \mathrm{CH}_{3} \mathrm{NH}\left(\mathrm{CH}_{2}\right)_{5} \mathrm{CH}_{3}$ & 1.8 & $98 \pm 3$ & $95 \pm 2$ & $71 \pm 10$ & $72 \pm 8$ & $>18.2$ \\
\hline & & 18.2 & $27 \pm 8$ & $22 \pm 3$ & $60 \pm 9$ & $66 \pm 10$ & \\
\hline & & 182 & $4 \pm 4$ & $2 \pm 5$ & $43 \pm 3$ & $44 \pm 8$ & \\
\hline 17 & $(\mathrm{CH}) \mathrm{CH}_{3} \mathrm{NH}\left(\mathrm{CH}_{2}\right)_{3} \mathrm{~N}\left(\mathrm{CH}_{3}\right)_{2}$ & 1.8 & $55 \pm 5$ & $31 \pm 7$ & $59 \pm 9$ & $46 \pm 8$ & 2.0 \\
\hline & & 18.2 & $28 \pm 3$ & $12 \pm 7$ & $35 \pm 10$ & $25 \pm 6$ & \\
\hline & & 182 & $6 \pm 1$ & $6 \pm 3$ & $21 \pm 3$ & $6 \pm 5$ & \\
\hline 19 & $\mathrm{CH}_{3}$ & 3.1 & $106 \pm 11$ & $100 \pm 8$ & $98 \pm 10$ & $94 \pm 7$ & $>31.0$ \\
\hline & & 31 & $70 \pm 10$ & $85 \pm 12$ & $68 \pm 3$ & $65 \pm 4$ & \\
\hline & & 310 & $52 \pm 9$ & $53 \pm 13$ & $40 \pm 2$ & $36 \pm 5$ & \\
\hline 20 & $\mathrm{CH}_{2} \mathrm{CH}_{3}$ & 2.6 & $52 \pm 9$ & $52 \pm 7$ & $40 \pm 9$ & $39 \pm 11$ & $>26.4$ \\
\hline & & 26.4 & $29 \pm 4$ & $30 \pm 3$ & $10 \pm 4$ & $14 \pm 9$ & \\
\hline & & 264 & $18 \pm 5$ & $16 \pm 4$ & $9 \pm 6$ & $5 \pm 9$ & \\
\hline 21 & $3-\mathrm{C}_{6} \mathrm{H}_{4} \mathrm{CH}_{3}$ & 2.1 & $90 \pm 11$ & $84 \pm 9$ & $80 \pm 5$ & $83 \pm 3$ & $>21.1$ \\
\hline & & 21.1 & $61 \pm 8$ & $52 \pm 8$ & $52 \pm 3$ & $39 \pm 8$ & \\
\hline & & 211 & $18 \pm 7$ & $18 \pm 4$ & $17 \pm 5$ & $18 \pm 7$ & \\
\hline 22 & $\mathrm{C}_{6} \mathrm{H}_{10}$ (cyclohexane) & 2.2 & $89 \pm 7$ & $84 \pm 6$ & $71 \pm 5$ & $66 \pm 12$ & $>21.8$ \\
\hline & & 21.8 & $92 \pm 3$ & $84 \pm 5$ & $68 \pm 7$ & $73 \pm 8$ & \\
\hline
\end{tabular}


Table 1. Continued

\begin{tabular}{|c|c|c|c|c|c|c|c|}
\hline \multirow{2}{*}{ Compd. } & \multirow[b]{2}{*}{$\mathrm{R}$} & \multirow{2}{*}{$\begin{array}{l}\text { Concn. } \\
(\mu \mathrm{M})^{a)}\end{array}$} & \multicolumn{2}{|c|}{$\mathrm{P}_{\text {hTERT }}{ }^{-S E A P}(\text { hTERT-BJ1) })^{b)}$} & \multicolumn{2}{|c|}{$\left.\mathrm{P}_{\mathrm{hTERT}^{-}}-\mathrm{SEAP}(\mathrm{H} 1299)^{c}\right)$} & \multirow{2}{*}{$\begin{array}{l}\text { TRAP assay } \mathrm{IC}_{50} \\
(\mu \mathrm{M})\end{array}$} \\
\hline & & & $\begin{array}{c}\text { Viability } \\
(\%)\end{array}$ & $\begin{array}{c}\text { Relative SEAP } \\
\text { activity }(\%)\end{array}$ & $\begin{array}{l}\text { Viability } \\
(\%)\end{array}$ & $\begin{array}{c}\text { Relative SEAP } \\
\text { activity }(\%)\end{array}$ & \\
\hline 22 & $\mathrm{C}_{6} \mathrm{H}_{10}$ (cyclohexane) & 218 & $29 \pm 7$ & $26 \pm 4$ & $15 \pm 1$ & $10 \pm 7$ & \\
\hline \multirow[t]{3}{*}{23} & $\left(\mathrm{CH}_{2}\right)_{2} \mathrm{C}_{5} \mathrm{H}_{9}$ & 2.1 & $79 \pm 6$ & $72 \pm 3$ & $75 \pm 6$ & $52 \pm 11$ & $>20.6$ \\
\hline & & 20.6 & $81 \pm 5$ & $70 \pm 4$ & $73 \pm 6$ & $55 \pm 11$ & \\
\hline & & 206 & $19 \pm 2$ & $16 \pm 3$ & $15 \pm 2$ & $4 \pm 8$ & \\
\hline \multirow[t]{3}{*}{24} & $\mathrm{C}_{5} \mathrm{H}_{9}$ & 2.3 & $92 \pm 11$ & $87 \pm 4$ & $81 \pm 5$ & $84 \pm 9$ & $>23.2$ \\
\hline & & 23.2 & $92 \pm 8$ & $83 \pm 5$ & $65 \pm 4$ & $53 \pm 9$ & \\
\hline & & 232 & $9 \pm 6$ & $3 \pm 3$ & $14 \pm 2$ & $36 \pm 8$ & \\
\hline \multirow[t]{3}{*}{25} & $\mathrm{C}_{3} \mathrm{H}_{5}$ & 2.7 & $97 \pm 5$ & $89 \pm 6$ & $81 \pm 4$ & $68 \pm 8$ & $>26.7$ \\
\hline & & 26.7 & $59 \pm 7$ & $55 \pm 3$ & $46 \pm 3$ & $31 \pm 4$ & \\
\hline & & 267 & $40 \pm 3$ & $39 \pm 6$ & $22 \pm 3$ & $6 \pm 4$ & \\
\hline \multirow[t]{3}{*}{26} & trans $-\mathrm{CH}\left(\mathrm{CH}_{2}\right) \mathrm{CHC}_{6} \mathrm{H}_{5}$ & 1.9 & $34 \pm 10$ & $40 \pm 5$ & $79 \pm 5$ & $66 \pm 4$ & $>19.0$ \\
\hline & & 19 & $20 \pm 7$ & $15 \pm 4$ & $46 \pm 3$ & $45 \pm 9$ & \\
\hline & & 190 & $4 \pm 4$ & $3 \pm 5$ & $19 \pm 2$ & $3 \pm 5$ & \\
\hline \multirow[t]{3}{*}{27} & $\mathrm{CH}_{2} \mathrm{SC}_{6} \mathrm{H}_{5}$ & 1.9 & $76 \pm 7$ & $71 \pm 5$ & $80 \pm 4$ & $75 \pm 4$ & $>18.6$ \\
\hline & & 18.6 & $57 \pm 6$ & $50 \pm 4$ & $49 \pm 3$ & $46 \pm 9$ & \\
\hline & & 186 & $34 \pm 8$ & $41 \pm 6$ & $31 \pm 5$ & $24 \pm 8$ & \\
\hline \multirow[t]{3}{*}{31} & $\mathrm{CH}_{2} \mathrm{Cl}$ & 2.6 & $58 \pm 6$ & $60 \pm 5$ & $76 \pm 4$ & $79 \pm 5$ & $>25.6$ \\
\hline & & 25.6 & $42 \pm 5$ & $42 \pm 4$ & $17 \pm 6$ & $20 \pm 3$ & \\
\hline & & 256 & $5 \pm 7$ & $6 \pm 5$ & $4 \pm 5$ & $5 \pm 1$ & \\
\hline \multirow[t]{3}{*}{32} & $\mathrm{CH}_{2} \mathrm{CH}_{2} \mathrm{Cl}$ & 2.4 & $34 \pm 4$ & $33 \pm 7$ & $77 \pm 7$ & $81 \pm 3$ & $>23.9$ \\
\hline & & 23.9 & $22 \pm 5$ & $24 \pm 4$ & $57 \pm 5$ & $56 \pm 3$ & \\
\hline & & 239 & $10 \pm 7$ & $13 \pm 3$ & $24 \pm 4$ & $23 \pm 3$ & \\
\hline \multirow[t]{3}{*}{33} & $\mathrm{CH}_{2} \mathrm{NHCH}_{2} \mathrm{CH}_{3}$ & 2.4 & $63 \pm 5$ & $68 \pm 6$ & $59 \pm 6$ & $62 \pm 7$ & 0.1 \\
\hline & & 24.5 & $25 \pm 5$ & $21 \pm 3$ & $22 \pm 7$ & $24 \pm 6$ & \\
\hline & & 245 & $1 \pm 3$ & $4 \pm 7$ & $7 \pm 8$ & $4 \pm 3$ & \\
\hline \multirow[t]{3}{*}{34} & $\mathrm{CH}_{2} \mathrm{NH}\left(\mathrm{CH}_{2}\right)_{2} \mathrm{CH}_{3}$ & 2.3 & $61 \pm 5$ & $64 \pm 7$ & $67 \pm 7$ & $74 \pm 9$ & 2.0 \\
\hline & & 22.9 & $31 \pm 6$ & $33 \pm 7$ & $40 \pm 6$ & $41 \pm 13$ & \\
\hline & & 229 & $7 \pm 6$ & $8 \pm 6$ & $16 \pm 5$ & $8 \pm 4$ & \\
\hline \multirow[t]{3}{*}{35} & $\mathrm{CH}_{2} \mathrm{NH}\left(\mathrm{CH}_{2}\right)_{3} \mathrm{CH}_{3}$ & 2.2 & $63 \pm 10$ & $69 \pm 8$ & $70 \pm 9$ & $73 \pm 2$ & $>21.5$ \\
\hline & & 21.5 & $50 \pm 8$ & $45 \pm 5$ & $56 \pm 3$ & $54 \pm 2$ & \\
\hline & & 215 & $12 \pm 5$ & $14 \pm 7$ & $23 \pm 7$ & $20 \pm 3$ & \\
\hline \multirow[t]{3}{*}{39} & $\mathrm{CHCH}_{3} \mathrm{Cl}$ & 2.4 & $98 \pm 5$ & $100 \pm 5$ & $103 \pm 8$ & $98 \pm 7$ & $>23.9$ \\
\hline & & 23.9 & $45 \pm 7$ & $42 \pm 7$ & $57 \pm 8$ & $50 \pm 9$ & \\
\hline & & 239 & $25 \pm 6$ & $29 \pm 5$ & $19 \pm 9$ & $24 \pm 7$ & \\
\hline \multirow[t]{3}{*}{45} & $\mathrm{CH}_{3}$ & 3.1 & $89 \pm 8$ & $93 \pm 12$ & $89 \pm 5$ & $96 \pm 6$ & $>31.0$ \\
\hline & & 31 & $66 \pm 9$ & $65 \pm 11$ & $54 \pm 5$ & $51 \pm 5$ & \\
\hline & & 310 & $36 \pm 10$ & $45 \pm 13$ & $39 \pm 3$ & $40 \pm 6$ & \\
\hline \multirow[t]{3}{*}{46} & $\mathrm{C}_{6} \mathrm{H}_{5}$ & 2.2 & $54 \pm 9$ & $51 \pm 7$ & $57 \pm 10$ & $53 \pm 7$ & $>22.4$ \\
\hline & & 22.4 & $19 \pm 8$ & $15 \pm 9$ & $26 \pm 5$ & $19 \pm 5$ & \\
\hline & & 224 & $10 \pm 5$ & $7 \pm 6$ & $14 \pm 8$ & $16 \pm 6$ & \\
\hline \multirow[t]{3}{*}{47} & $\mathrm{C}_{6} \mathrm{H}_{4} \mathrm{Cl}-\mathrm{O}$ & 1.9 & $86 \pm 5$ & $89 \pm 6$ & $91 \pm 4$ & $98 \pm 5$ & $>19.4$ \\
\hline & & 19.4 & $88 \pm 8$ & $85 \pm 7$ & $89 \pm 12$ & $95 \pm 7$ & \\
\hline & & 194 & $39 \pm 4$ & $31 \pm 5$ & $31 \pm 11$ & $44 \pm 4$ & \\
\hline \multirow{3}{*}{\multicolumn{2}{|c|}{ Mitoxantrone }} & 1.9 & $75 \pm 2.9$ & $30 \pm 5.8$ & $100 \pm 5.6$ & $81 \pm 3.8$ & 2.0 \\
\hline & & 19 & $56 \pm 3.1$ & $13 \pm 9.2$ & $57 \pm 4.3$ & $66 \pm 4.0$ & \\
\hline & & 193 & $10 \pm 2.0$ & $4 \pm 14.2$ & $39 \pm 3.2$ & $47 \pm 3.9$ & \\
\hline
\end{tabular}

a) Values are in $\mu \mathrm{M}$ and represent an average of three experiments. b) The hTERT immortalized hTERT-BJ1 was purchased from BD Biosciences Clontech. The results in this column are shown as means \pm S.E. of experiments repeated five times. $c$ ) Values are mean percent activity at the indicated concentration, and standard errors. The variance for the relative viability $(\%)$ and relative SEAP activity $(\%)$ values was less than $\pm 20 \%$. All of SEAP data are shown as the result that drug-self interference has been subtracted.

be therapeutically useful, requires a lag period for cancer cells to stop proliferating in which compounds also have the ability to effectively discriminate between duplex and quadruplex DNA. Thus, the acute cytotoxicity of anthraquinones should not be caused solely by their effects on telomerase. Interestingly, our results showed that the spectrum of some anthraquinones for cytotoxicity and telomerase inhibitory are quite similar. These anthraquinones described here exhibit 1,5-diamidoanthraquinone 5 and 2,6-diamidoanthraquinones 33, 34 are potent cytotoxic compounds and effective telomerase inhibitors which have $\mathrm{IC}_{50}$ values in the low-micromolar range compared with mitoxantrone. They represent the first small-molecule structures of telomerase in- hibitors with this special type of property. The unique property of these anthraquinones make them as the best candidates for future developments of anticancer drugs. Mitoxantrone is useful for chemotherapy because it inhibits both DNA replication and DNA-dependent RNA synthesis by intercalating into DNA and causing crosslinking and strand breaks. $^{41,42)}$ It also inhibits topoisomerase II and consequently interferes with DNA repair. ${ }^{42-44)}$ Previous SAR studies have indicated the crucial role of diaminoalkyl group in side chains of anthraquinones for their cytotoxic activities, ${ }^{44,45}$ but the importance of this diaminoalkyl group for any of the proposed mechanisms of action is still not clear. The present cytotoxic studies on 1,5-diamido and 2,6-di- 
Table 2. Structures and Inhibition $\left(\mathrm{IC}_{50}\right)$ of Some Selected Telomerase-Inhibitory Anthraquinones

\begin{tabular}{|c|c|c|c|c|c|c|c|}
\hline \multirow[b]{2}{*}{ Isomers No. } & \multirow[b]{2}{*}{$\mathrm{R}$} & \multirow{2}{*}{$\begin{array}{l}\text { Concn. } \\
(\mu \mathrm{M})\end{array}$} & \multicolumn{2}{|c|}{$\mathrm{P}_{\text {hTERT }}$-SEAP (hTERT-BJ1) } & \multicolumn{2}{|c|}{$\mathrm{P}_{\text {hTERT }}$-SEAP (H1299) } & \multirow{2}{*}{$\begin{array}{l}\text { TRAP assay } \\
\mathrm{IC}_{50}(\mu \mathrm{M})\end{array}$} \\
\hline & & & $\begin{array}{l}\text { Viability } \\
\text { (\%) }\end{array}$ & $\begin{array}{c}\text { Relative SEAP } \\
\text { activity (\%) }\end{array}$ & $\begin{array}{l}\text { Viability } \\
\text { (\%) }\end{array}$ & $\begin{array}{c}\text { Relative SEAP } \\
\text { activity (\%) }\end{array}$ & \\
\hline \multirow[t]{3}{*}{ 1,4-diamido 20$)$} & \multirow[t]{3}{*}{$\mathrm{CH}_{2} \mathrm{CH}_{2} \mathrm{~N}\left(\mathrm{CH}_{2} \mathrm{CH}_{3}\right)_{2}$} & 2.0 & $83 \pm 9.2$ & $2 \pm 11.1$ & $92 \pm 6.1$ & $73 \pm 2.7$ & \multirow[t]{3}{*}{2.0} \\
\hline & & 20 & $15 \pm 3.9$ & $(-2) \pm 11.2$ & $11 \pm 2.5$ & $53 \pm 2.7$ & \\
\hline & & 203 & $6 \pm 3.9$ & $(-2) \pm 6.5$ & $1 \pm 2.4$ & $39 \pm 0.8$ & \\
\hline \multirow[t]{3}{*}{ 1,4-diamido ${ }^{20)}$} & \multirow[t]{3}{*}{$2,4,6-\mathrm{Cl}_{3} \mathrm{C}_{6} \mathrm{H}_{2}$} & 1.5 & $98 \pm 8.5$ & $31 \pm 23.0$ & $113 \pm 4.8$ & $98 \pm 4.5$ & \multirow[t]{3}{*}{40} \\
\hline & & 15 & $63 \pm 7.0$ & $12 \pm 12.5$ & $107 \pm 5.4$ & $66 \pm 2.4$ & \\
\hline & & 153 & $40 \pm 22.2$ & $4 \pm 15$ & $20 \pm 3.3$ & $41 \pm 3.9$ & \\
\hline \multirow{3}{*}{$\begin{array}{c}\text { 1,5-diamido } \\
\mathbf{5}\end{array}$} & \multirow[t]{3}{*}{$\mathrm{CH}_{2} \mathrm{NHCH}_{2} \mathrm{CH}_{3}$} & 2.4 & $28 \pm 5$ & $31 \pm 5$ & $30 \pm 5$ & $33 \pm 4$ & \multirow[t]{3}{*}{5.0} \\
\hline & & 24.5 & $18 \pm 5$ & $20 \pm 5$ & $9 \pm 6$ & $12 \pm 7$ & \\
\hline & & 245 & $12 \pm 6$ & $11 \pm 7$ & $8 \pm 4$ & $6 \pm 5$ & \\
\hline \multirow{3}{*}{$\begin{array}{c}\text { 1,5-diamido } \\
\mathbf{1 7}\end{array}$} & \multirow[t]{3}{*}{$(\mathrm{CH}) \mathrm{CH}_{3} \mathrm{NH}\left(\mathrm{CH}_{2}\right)_{3} \mathrm{~N}\left(\mathrm{CH}_{3}\right)_{2}$} & 1.8 & $55 \pm 5$ & $31 \pm 7$ & $59 \pm 9$ & $46 \pm 8$ & \multirow[t]{3}{*}{2.0} \\
\hline & & 18.2 & $28 \pm 3$ & $12 \pm 7$ & $35 \pm 10$ & $25 \pm 6$ & \\
\hline & & 182 & $6 \pm 1$ & $6 \pm 3$ & $21 \pm 3$ & $6 \pm 5$ & \\
\hline \multirow{3}{*}{$\begin{array}{l}\text { 2,6-diamido } \\
\mathbf{3 3}\end{array}$} & \multirow{3}{*}{$\mathrm{CH}_{2} \mathrm{NHCH}_{2} \mathrm{CH}_{3}$} & 2.4 & $63 \pm 5$ & $68 \pm 6$ & $59 \pm 6$ & $62 \pm 7$ & \multirow[t]{3}{*}{0.1} \\
\hline & & 24.5 & $25 \pm 5$ & $21 \pm 3$ & $22 \pm 7$ & $24 \pm 6$ & \\
\hline & & 245 & $1 \pm 3$ & $4 \pm 7$ & $7 \pm 8$ & $4 \pm 3$ & \\
\hline \multirow{3}{*}{$\begin{array}{l}\text { 2,6-diamido } \\
\mathbf{3 4}\end{array}$} & \multirow[t]{3}{*}{$\mathrm{CH}_{2} \mathrm{NH}\left(\mathrm{CH}_{2}\right)_{2} \mathrm{CH}_{3}$} & 2.3 & $61 \pm 5$ & $64 \pm 7$ & $67 \pm 7$ & $74 \pm 9$ & \multirow[t]{3}{*}{2.0} \\
\hline & & 22.9 & $31 \pm 6$ & $33 \pm 7$ & $40 \pm 6$ & $41 \pm 13$ & \\
\hline & & 229 & $7 \pm 6$ & $8 \pm 6$ & $16 \pm 5$ & $8 \pm 4$ & \\
\hline \multirow[t]{3}{*}{ 1,5-diamino ${ }^{20)}$} & \multirow[t]{3}{*}{$\mathrm{CH}_{2} \mathrm{CH}_{2} \mathrm{~N}\left(\mathrm{CH}_{3}\right)_{2}$} & 2.6 & $92 \pm 4.8$ & $11 \pm 22.4$ & $107 \pm 9.1$ & $103 \pm 6.0$ & 20 \\
\hline & & 26 & $76 \pm 5.9$ & $-15 \pm 18.2$ & $81 \pm 8.3$ & $54 \pm 5.9$ & \\
\hline & & 262 & $7 \pm 18.2$ & $-26 \pm 16.9$ & $29 \pm 2.6$ & $40 \pm 5.9$ & \\
\hline 1,5-diamino ${ }^{20)}$ & $\mathrm{CH}_{2} \mathrm{CH}_{2} \mathrm{NH}\left(\mathrm{CH}_{2}\right)_{2} \mathrm{OH}$ & 2.4 & $84 \pm 19.8$ & $60 \pm 11.6$ & $97 \pm 8.7$ & $87 \pm 3.8$ & 0.2 \\
\hline & & 24 & $60 \pm 11.2$ & $40 \pm 17.3$ & $37 \pm 3.9$ & $43 \pm 5.5$ & \\
\hline & & 242 & $44 \pm 12.9$ & $52 \pm 19.1$ & $11 \pm 4.1$ & $40 \pm 6.7$ & \\
\hline 1,5-diamino ${ }^{20)}$ & $\mathrm{CH}_{2} \mathrm{CH}_{2} \mathrm{CH}_{2} \mathrm{OH}$ & 2.8 & $72 \pm 7.4$ & $41 \pm 12.5$ & $107 \pm 5.0$ & $88 \pm 4.9$ & 30 \\
\hline & & 28 & $39 \pm 10.5$ & $0 \pm 22.1$ & $49 \pm 3.5$ & $69 \pm 5.4$ & \\
\hline & & 282 & $26 \pm 15.9$ & $-3 \pm 10.0$ & $40 \pm 10.4$ & $33 \pm 2.2$ & \\
\hline 1,5 -diamino ${ }^{20)}$ & $\mathrm{CH}_{2} \mathrm{CH}_{2} \mathrm{CH}_{2} \mathrm{NH}_{2}$ & 2.8 & $85 \pm 6.9$ & $103 \pm 19.8$ & $85 \pm 11.5$ & $102 \pm 4.9$ & 0.5 \\
\hline & & 28 & $3 \pm 6.9$ & $47 \pm 20.5$ & $32 \pm 9.3$ & $44 \pm 7.5$ & \\
\hline & & 283 & $(-2) \pm 7.7$ & $60 \pm 15.1$ & $16 \pm 2.1$ & $38 \pm 6.0$ & \\
\hline 1,5 -diamino ${ }^{20)}$ & $\mathrm{CH}_{2} \mathrm{CH}_{2} \mathrm{CH}_{2} \mathrm{CH}_{2} \mathrm{NH}_{2}$ & 2.6 & $101 \pm 10.5$ & $114 \pm 20.5$ & $114 \pm 8.1$ & $89 \pm 4.9$ & 5.0 \\
\hline & & 26 & $101 \pm 8.8$ & $113 \pm 21.6$ & $110 \pm 7.1$ & $71 \pm 9.8$ & \\
\hline & & 265 & $91 \pm 11.8$ & $127 \pm 19.9$ & $16 \pm 3.4$ & $27 \pm 2.0$ & \\
\hline & Mitoxantrone & 1.9 & $75 \pm 2.9$ & $30 \pm 5.8$ & $100 \pm 5.6$ & $81 \pm 3.8$ & 2.0 \\
\hline & & 19 & $56 \pm 3.1$ & $13 \pm 9.2$ & $57 \pm 4.3$ & $66 \pm 4.0$ & \\
\hline & & 193 & $10 \pm 2.0$ & $4 \pm 14.2$ & $39 \pm 3.2$ & $47 \pm 3.9$ & \\
\hline
\end{tabular}

amido-anthraquinones indicated that many of them are more effective than mitoxantrone at concentration 4-20 fold lower. Our result is consistent with early SAR analysis that diaminoanthraquinones are effective cytotoxic agents. Since our results showed that 1,5-diamidoanthraquinone 5 and 2,6diamidoanthraquinones 33, 34 have multiple functions on cells. In addition to their telomerase inhibitory effects, they might affect cancer cells in a way similar to that of mitoxantrone. It is also noteworthy that more 1,5-diamidoanthraquinones were identified as effective cytotoxic agents than 2,6-diamidoanthraquinones. Keppler et al. ${ }^{17)}$ have also indicated that anthraquinones interacted with duplex DNA in molecular modeling studies and have examined how the position of the attached base-functionalized substituents affects their ability to stabilize DNA duplexes. The apparent bias might provide a direction for future design of anthraquinonebased anticancer agents.

Substitutions on the planar ring of anthraquinone have been shown to have various effects on G-quadruplex formation. Perry and Neidle ${ }^{25}$ have shown that amidoanthraquinones favoring duplex binding are related to the inhibition of telomerase activity and assumed to be nonselective. In our previous papers, we reported the inhibitory effects of human telomerase by a series of difunctionalized substituted anthraquinone derivatives..$^{20,27,30,46-49)}$ From a SAR point of view cytotoxicity is evident from the remarkable results presented here and previously reported. In combination with our present studies on a range of 2,6-diamidoanthraquinones and 1,5-diamidoanthraquinones in inhibiting telomerase activity, some indications of SARs for telomerase inhibition are evident. For example, the most active compound from the TRAP assay, with a $\mathrm{IC}_{50}$ of $0.1 \mu \mathrm{M}$, is the $2-(N-$ ethylamino)acetamido side chains of 2,6-diamidoanthraquinone 33. This is thus among the most potent nonnucleoside telomerase inhibitors reported to date. 1,5-Diaminoanthraquinones $\mathbf{6}$ and $\mathbf{1 0}$ with $\mathrm{CH}_{2} \mathrm{CH}_{2} \mathrm{NH}\left(\mathrm{CH}_{2}\right)_{2} \mathrm{OH}$ 
and $\mathrm{CH}_{2} \mathrm{CH}_{2} \mathrm{CH}_{2} \mathrm{NH}_{2}$ side chains also show good inhibition of telomerase at $\mathrm{IC}_{50}$ level of 0.2 and $0.5 \mu \mathrm{M}$, respectively. The activities of the 1,5-diamidoanthraquinone 17 with (CH) $\mathrm{CH}_{3} \mathrm{NH}\left(\mathrm{CH}_{2}\right)_{3} \mathrm{~N}\left(\mathrm{CH}_{3}\right)_{2}$ side chains, 2,6-diamidoanthraquinone 34 with $\mathrm{CH}_{2} \mathrm{NH}\left(\mathrm{CH}_{2}\right)_{2} \mathrm{CH}_{3}$ side chains, and 1,4-diamidoanthraquinone with $\mathrm{CH}_{2} \mathrm{CH}_{2} \mathrm{~N}\left(\mathrm{CH}_{2} \mathrm{CH}_{3}\right)_{2}$ side chains show telomerase activity at levels similar to mitoxantrone with $\mathrm{IC}_{50}$ value of $2.0 \mu \mathrm{M}$. Even with substitutions at different positions, these derivatives share a common feature with bulky long substituent at the terminus of the side chain. This feature may be important for inhibition of telomerase activity, at least in the 2,6-diamidoanthraquinones, 1,4-diamidoanthraquinones, and 1,5-diamidoanthraquinones series examined. Molecular modeling studies suggested that the tricyclic structure of anthraquinone bound to the terminal guanine-quartet. ${ }^{26,50,51)}$ Substitutions of anthraquinones then bound to the DNA grooves to further stabilize the complex. ${ }^{9)}$ The bulky long substitutions of anthraquinones might serve as two arms to stabilize the interactions between these compounds and G-quadruplex structures.

We have previously shown that 1,5 -diaminoanthraquinones have good telomerase inhibition using TRAP assay. However, the present study shows that 2,6-diamidoanthraquinone $\mathbf{3 3}$ significantly inhibit telomerase activity. In common with other similarly behaving compounds in Tables 1 and 2, it was evaluated in the TRAP assay in view of its potential nonselective affinity for DNA polymerase. The crystal structure of $\mathrm{Taq}$ polymerase indicates that its active site shares at least some common features with other DNA polymerases. ${ }^{52,53)}$ If such compounds are to have applications as antitumor agents, with telomerase inhibition in tumor cells leading to the attrition of telomere length and consequent senescence. By contrast the established anthraquinone-based anticancer drugs mitoxantrone, even though it shows telomerase activity at levels $2.0 \mu \mathrm{M}$. It is also noteworthy that the tricyclic anthraquinone structure motif itself might contribute to the biological activity. The telomerase effects induced by anthraquinone derivatives do not closely resemble what we previously reported. ${ }^{20,27)}$ As a whole, these data support the conclusion that all the tested molecules, including those reported here, share a common target in telomerase. These results confirm once more the view that tricyclic anthraquinone pharmacophore targeting telomerase, DNA-interactive and fold into a wide variety of four-stranded quadruplex structures may be regarded as novel potential anticancer agents.

\section{Experimental}

Melting points were determined with a Büchi 530 melting point apparatus and are uncorrected. All reactions were monitored by TLC, which were performed on precoated sheets on silica gel $60 \mathrm{~F}_{254}$, and flash column chromatography was done in silica gel (E. Merck, $70-230$ mesh) with $\mathrm{CH}_{2} \mathrm{Cl}_{2}$ as eluant, unless otherwise stated. ${ }^{1} \mathrm{H}$-NMR spectra were recorded with a Varian GEMINI-300 $(300 \mathrm{MHz}) . \delta$ values are in ppm relative to a tetramethylsilane internal standard. Fourier transform IR spectra $(\mathrm{KBr})$ were recorded on a Perkin-Elmer 983G spectrometer. Mass spectra (EI, $70 \mathrm{eV}$, unless otherwise stated) were obtained on a Finnigan MAT TSQ-46 and Finnigan MAT TSQ-700. The following 1,5-diamidoanthraquinones (2-27) were prepared by previously described procedures. ${ }^{31)}$ All other compounds were commercial materials.

General Procedure for the Preparation of 2,6-Diamidoanthraquinone Derivatives Acylation (Compounds 31-32, 39, 45-47): Chloroacyl chloride $(12 \mathrm{mmol})$ was added dropwise at $0{ }^{\circ} \mathrm{C}$ under $\mathrm{N}_{2}$ to a solution of 2,6-diaminoanthraquinone $(1 \mathrm{mmol})$ and pyridine $(0.5 \mathrm{ml})$ in $N, N$-dimethylformamide $(20 \mathrm{ml})$. The reaction mixture was stirred for $24 \mathrm{~h}$ at room tem- perature under $\mathrm{N}_{2}$. The resulting precipitate was collected by filtration, washed with diethyl ether and purified by crystallization from ethyl acetate to afford desired compounds.

Amination (Compounds 33-38, 40-44): A solution of an appropriate amines $(20 \mathrm{mmol})$ in DMF was added dropwise under $\mathrm{N}_{2}$ to a suspended solution of compounds 31-32, or $\mathbf{3 9}$ (1 mmol) in $40 \mathrm{ml}$ of DMF and triethylamine $(0.5 \mathrm{ml})$. The reaction mixture was heated and refluxed at $130{ }^{\circ} \mathrm{C}$ in miniclave $\left(\mathrm{Büchi}^{\mathbb{B}}\right)$ for $1 \mathrm{~h}$. After cooling and the reaction mixture was treated with crushed ice and the resulting precipitate was collected by filtration, washed and purified by crystallization from ethyl acetate to afford desired compounds.

2,6-Bis(2-chloroacetamido)anthraquinone (31) $90 \%$ yield. mp $323^{\circ} \mathrm{C}$ (Ethanol). ${ }^{1} \mathrm{H}-\mathrm{NMR}\left(\mathrm{CDCl}_{3}\right): \delta: 4.35\left(4 \mathrm{H}, \mathrm{s}, \mathrm{CH}_{2}\right), 8.06(2 \mathrm{H}, \mathrm{d}, J=8.4 \mathrm{~Hz})$, $8.18(2 \mathrm{H}, \mathrm{d}, J=8.4 \mathrm{~Hz}), 8.42(2 \mathrm{H}, \mathrm{s}), 10.94(2 \mathrm{H}, \mathrm{s}, \mathrm{NH}) .{ }^{13} \mathrm{C}-\mathrm{NMR}\left(\mathrm{CDCl}_{3}\right)$ : $\delta: 181.30,165.67,144.09,134.46,128.71,128.71,123.89,116.25,43.68$, 40.53, 39.96, 39.70, 39.41, 39.14, 38.86. IR (KBr) cm ${ }^{-1}: 1695,3300 . \mathrm{MS}$ $\mathrm{m} / \mathrm{z}: 394\left(\mathrm{M}^{+}\right), 393,392,391,389.9,314,238$.

2,6-Bis(2-chloropropionamido)anthraquinone (32) $90 \%$ yield. $\mathrm{mp}$ $186{ }^{\circ} \mathrm{C}$ (Ethanol). ${ }^{1} \mathrm{H}-\mathrm{NMR}\left(\mathrm{CDCl}_{3}\right): \delta: 2.92\left(2 \mathrm{H}, \mathrm{t}, J=6.9 \mathrm{~Hz}, \mathrm{CH}_{2}\right), 3.91$ $\left(2 \mathrm{H}, \mathrm{t}, J=6.3 \mathrm{~Hz}, \mathrm{CH}_{2}\right), 8.08(2 \mathrm{H}, \mathrm{d}, J=8.4 \mathrm{~Hz}), 8.17(2 \mathrm{H}, \mathrm{d}, J=8.4 \mathrm{~Hz})$, $8.45(2 \mathrm{H}, \mathrm{s}), 10.88(2 \mathrm{H}, \mathrm{s}, \mathrm{NH}) .{ }^{13} \mathrm{C}-\mathrm{NMR}\left(\mathrm{CDCl}_{3}\right): \delta: 181.33,169.04$, 144.46, 134.45, 128.61, 128.26, 123.56, 115.98, 40.53, 40.26, 39.96, 39.70, 39.43, 39.14, 38.87. IR (KBr) cm $\mathrm{cm}^{-1}: 1666,3098$. MS $m / z: 419\left(\mathrm{M}^{+}\right), 389$, 314.

2,6-Bis(2-ethylaminoacetamido)anthraquinone (33) $87 \%$ yield. $\mathrm{mp}$ $379^{\circ} \mathrm{C}$ (Ethanol). ${ }^{1} \mathrm{H}-\mathrm{NMR}\left(\mathrm{CDCl}_{3}\right): \delta: 0.88\left(6 \mathrm{H}, \mathrm{t}, J=6.9 \mathrm{~Hz}, \mathrm{CH}_{3}\right), 1.42-$ $1.49\left(4 \mathrm{H}, \mathrm{m}, \mathrm{CH}_{2}\right), 2.51\left(4 \mathrm{H}, \mathrm{t}, J=6.3 \mathrm{~Hz}, \mathrm{CH}_{2}\right), 8.09(2 \mathrm{H}, \mathrm{d}, J=9.0 \mathrm{~Hz})$, $8.16(2 \mathrm{H}, \mathrm{d}, J=8.4 \mathrm{~Hz}), 8.49(2 \mathrm{H}, \mathrm{s}) \cdot{ }^{13} \mathrm{C}-\mathrm{NMR}\left(\mathrm{CDCl}_{3}\right): \delta: 181.37,171.59$, $144.30,134.46,128.52,128.22,123.67,116.40,53.08,43.65,40.84,40.56$, 40.28, 40.01, 39.72, 39.45, 39.17, 15.29. IR (KBr) cm${ }^{-1}: 1585,1700,2956$, 3282. MS $m / z: 408\left(\mathrm{M}^{+}\right), 346,292$.

2,6-Bis(2-propylamino)ethanamido)anthraquinone (34) $80 \%$ yield. $\mathrm{mp} 149^{\circ} \mathrm{C}$ (Ethanol). ${ }^{1} \mathrm{H}-\mathrm{NMR}\left(\mathrm{CDCl}_{3}\right): \delta: 0.88(6 \mathrm{H}, \mathrm{t}, J=6.9 \mathrm{~Hz}), 1.42$ $1.49(4 \mathrm{H}, \mathrm{m}), 2.49-2.51(4 \mathrm{H}, \mathrm{m}), 3.34(4 \mathrm{H}, \mathrm{d}), 8.07(2 \mathrm{H}, \mathrm{d}, J=9.0 \mathrm{~Hz})$, $8.16(2 \mathrm{H}, \mathrm{d}, J=8.4 \mathrm{~Hz}), 8.49(2 \mathrm{H}, \mathrm{s}) .{ }^{13} \mathrm{C}-\mathrm{NMR}\left(\mathrm{CDCl}_{3}\right): \delta: 181.37,171.59$, $144.30,134.45,128.52,128.22,123.67,116.02,53.01,51.06,40.54,40.26$, 39.98, 39.70, 39.43, 39.14, 38.87, 22.63, 11.75. IR (KBr) cm ${ }^{-1}: 1589,1652$, 1700, 2956, 3282. MS $m / z: 436\left(\mathrm{M}^{+}\right), 337,238$.

2,6-Bis(2- $N$-n-butylaminoacetamido)anthraquinone (35) $76 \%$ yield $\mathrm{mp} 171^{\circ} \mathrm{C}$ (Ethanol). ${ }^{1} \mathrm{H}-\mathrm{NMR}\left(\mathrm{CDCl}_{3}\right): \delta: 0.87\left(6 \mathrm{H}, \mathrm{t}, J=7.2 \mathrm{~Hz}, \mathrm{CH}_{3}\right)$, $1.28-1.36\left(4 \mathrm{H}, \mathrm{m}, \mathrm{CH}_{2}\right), 1.38-1.45\left(4 \mathrm{H}, \mathrm{m}, \mathrm{CH}_{2}\right), 2.48-2.56(4 \mathrm{H}, \mathrm{m}$, $\left.\mathrm{CH}_{2}\right), 3.33\left(4 \mathrm{H}, \mathrm{d}, J=7.0 \mathrm{~Hz}, \mathrm{CH}_{2}\right), 8.08(2 \mathrm{H}, \mathrm{dd}, J=6.6,2.1 \mathrm{~Hz}),, 8.15(2 \mathrm{H}$, d, $J=8.4 \mathrm{~Hz}), 8.48(2 \mathrm{H}, \mathrm{d}, J=1.8 \mathrm{~Hz}) \cdot{ }^{13} \mathrm{C}-\mathrm{NMR}\left(\mathrm{CDCl}_{3}\right): \delta: 181.37(\mathrm{CO})$, 171.63 (NCO), 151.52, 144.31, 134.44, 128.52, 128.21, 123.66, 116.02, 53.11, 48.80, 40.54, 40.26, 39.98, 39.70, 39.43, 39.14, 38.87, 31.70, 19.92, 13.93. IR (KBr) cm ${ }^{-1}: 1595,1655,1705,2965,3285$. MS $m / z: 464\left(\mathrm{M}^{+}\right)$, 351.

2,6-Bis(2- $N$-pentylaminoacetamido)anthraquinone (36) $77 \%$ yield. mp $159^{\circ} \mathrm{C}$ (Ethanol). ${ }^{1} \mathrm{H}-\mathrm{NMR}\left(\mathrm{CDCl}_{3}\right): \delta: 0.86\left(6 \mathrm{H}, \mathrm{t}, J=6.9 \mathrm{~Hz}, \mathrm{CH}_{3}\right)$, $1.28\left(8 \mathrm{H}, \mathrm{t}, J=6.8 \mathrm{~Hz}, \mathrm{CH}_{2}\right), 1.43\left(4 \mathrm{H}, \mathrm{t}, J=6.8 \mathrm{~Hz}, \mathrm{CH}_{2}\right), 2.51(8 \mathrm{H}, \mathrm{t}$, $J=6.8 \mathrm{~Hz}), 8.08(2 \mathrm{H}, \mathrm{dd}, J=8.7,1.5 \mathrm{~Hz}), 8.14(2 \mathrm{H}, \mathrm{d}, J=8.4 \mathrm{~Hz}), 8.46(2 \mathrm{H}$ d, $J=1.8 \mathrm{~Hz}) .{ }^{13} \mathrm{C}-\mathrm{NMR}\left(\mathrm{CDCl}_{3}\right): \delta 181.37,171.66,144.34,134.45,128.54$, $128.21,123.66,116.03,53.14,49.16,40.54,40.26,39.98,39.70,39.43$, $39.15,38.87,29.22,29.06,22.13,14.02$. IR $(\mathrm{KBr}) \mathrm{cm}^{-1}: 1690,1700,3285$. MS $m / z: 492\left(\mathrm{M}^{+}\right), 365,266,238$.

2,6-Bis(2- $N$-hexylaminoacetamido)anthraquinone (37) $77 \%$ yield. $\mathrm{mp} 135^{\circ} \mathrm{C}$ (Ethanol). ${ }^{1} \mathrm{H}-\mathrm{NMR}\left(\mathrm{CDCl}_{3}\right): \delta: 0.84\left(\mathrm{t}, 6 \mathrm{H}, J=6.6 \mathrm{~Hz}, \mathrm{CH}_{3}\right)$, $1.25-1.43\left(18 \mathrm{H}, \mathrm{m}, \mathrm{CH}_{2}\right), 2.53\left(4 \mathrm{H}, \mathrm{t}, J=7.2 \mathrm{~Hz}, \mathrm{CH}_{2}\right), 3.34\left(2 \mathrm{H}, \mathrm{s}, \mathrm{CH}_{2}\right)$, $8.08(2 \mathrm{H}, \mathrm{dd}, J=8.7,1.8 \mathrm{~Hz}), 8.15(2 \mathrm{H}, \mathrm{d}, J=7.8 \mathrm{~Hz}), 8.47(2 \mathrm{H}, \mathrm{d}$, $J=1.8 \mathrm{~Hz}) \cdot{ }^{13} \mathrm{C}-\mathrm{NMR}\left(\mathrm{CDCl}_{3}\right): \delta: 181.35,171.66,144.33,134.44,128.50$, $128.19,123.65,116.02,53.14,49.18,40.53,40.26,39.98,39.70,39.43$, 39.14, 38.87, 31.29, 29.51, 26.47, 22.14, 13.96. IR $(\mathrm{KBr}) \mathrm{cm}^{-1}: 1695,2909$, 3339. MS $m / z: 520\left(\mathrm{M}^{+}\right), 405,379,238$.

2,6-Bis(2- $N$-ethylaminopropionamido)anthraquinone (38) $75 \%$ yield. mp $349^{\circ} \mathrm{C}$ (Ethanol). ${ }^{1} \mathrm{H}-\mathrm{NMR}\left(\mathrm{CDCl}_{3}\right): \delta: 1.00\left(6 \mathrm{H}, \mathrm{t}, J=7.5 \mathrm{~Hz}, \mathrm{CH}_{3}\right)$, $2.47-2.57(8 \mathrm{H}, \mathrm{m}), 2.80(4 \mathrm{H}, \mathrm{t}, J=6.6 \mathrm{~Hz}), 8.02(2 \mathrm{H}, \mathrm{d}, J=8.4 \mathrm{~Hz}), 8.12$ $(2 \mathrm{H}, \mathrm{d}, J=8.7 \mathrm{~Hz}), 8.38(2 \mathrm{H}, \mathrm{s}) .{ }^{13} \mathrm{C}-\mathrm{NMR}\left(\mathrm{CDCl}_{3}\right): \delta: 181.37,171.62$, $144.81,134.44,128.55,127.98,123.41,115.83,45.06,43.26,40.54,40.26$, $39.98,39.70,39.43,39.15,38.87,37.27,15.21$. IR (KBr) cm ${ }^{-1}: 1700,2910$, 3340. MS $m / z: 436\left(\mathrm{M}^{+}\right), 346,292,238$.

2,6-Bis(2-chloropropionamido)anthraquinone (39) $90 \%$ yield. $\mathrm{mp}$ $290^{\circ} \mathrm{C}$ (Ethanol). ${ }^{1} \mathrm{H}-\mathrm{NMR}\left(\mathrm{CDCl}_{3}\right): \delta: 1.65\left(6 \mathrm{H}, \mathrm{d}, J=6.9 \mathrm{~Hz}, \mathrm{CH}_{3}\right), 4.72$ $(2 \mathrm{H}, \mathrm{q}, J=6.6 \mathrm{~Hz}, \mathrm{CH}), 8.09(2 \mathrm{H}, \mathrm{dd}, J=6.6 \mathrm{~Hz}), 8.20(2 \mathrm{H}, \mathrm{d}, J=8.1 \mathrm{~Hz})$, $8.46(2 \mathrm{H}, \mathrm{s}) .{ }^{13} \mathrm{C}-\mathrm{NMR}\left(\mathrm{CDCl}_{3}\right): \delta: 181.30,168.29,144.15,134.46,128.71$, 
$127.98,124.37,116.43,54.76,20.93$. IR (KBr) $\mathrm{cm}^{-1}: 1671,2910,3340 . \mathrm{MS}$ $m / z: 419\left(\mathrm{M}^{+}\right), 348$.

2,6-Bis(benzamido)anthraquinone (46) $75 \%$ yield. $\quad \mathrm{mp} \quad 321^{\circ} \mathrm{C}$ (Ethanol). ${ }^{1} \mathrm{H}-\mathrm{NMR}\left(\mathrm{CDCl}_{3}\right): \delta: 7.54-7.64(6 \mathrm{H}, \mathrm{m}, \mathrm{CH}), 8.02(2 \mathrm{H}, \mathrm{d}$, $J=8.1 \mathrm{~Hz}), 8.23(4 \mathrm{H}, \mathrm{d}, J=8.1 \mathrm{~Hz}), 8.34(2 \mathrm{H}, \mathrm{d}, J=8.7 \mathrm{~Hz}), 8.67(2 \mathrm{H}, \mathrm{s}, \mathrm{Ar}-$ $\mathrm{H}), 10.86(2 \mathrm{H}, \mathrm{s}, \mathrm{NH}) .{ }^{13} \mathrm{C}-\mathrm{NMR}\left(\mathrm{CDCl}_{3}\right): \delta: 181.30,166.26,144.95$, $134.28,132.19,128.56,128.41,127.97,124.61,117.19$. IR $(\mathrm{KBr}) \mathrm{cm}^{-1}$ : 1580, 1690, 3320. MS $m / z: 446\left(\mathrm{M}^{+}\right), 105$

2,6-Bis(2-chlorobenzamido)anthraquinone (47) $80 \%$ yield. mp $343^{\circ} \mathrm{C}$ (Ethanol). ${ }^{1} \mathrm{H}-\mathrm{NMR}\left(\mathrm{CDCl}_{3}\right): \delta: 7.49-7.62(6 \mathrm{H}, \mathrm{m}, \mathrm{CH}), 7.67(2 \mathrm{H}$, $\mathrm{d}, J=7.5 \mathrm{~Hz}), 8.18(4 \mathrm{H}, \mathrm{d}, J=8.1 \mathrm{~Hz}), 8.23(2 \mathrm{H}, \mathrm{d}, J=8.1 \mathrm{~Hz}), 8.62(2 \mathrm{H}, \mathrm{s}$, Ar-H), 11.17 (2H, s, NH). IR (KBr) $\mathrm{cm}^{-1}: 1690,2363,3320$. MS m/z: 516 $\left(\mathrm{M}^{+}\right), 141,139$.

Cell Culture and Assessment of hTERT Nonsmall lung cancer cells H1299 (telomerase positive) were grown in RPMI 1640 media supplemented with $10 \%$ fetal bovine serum, 100 units $/ \mathrm{ml}$ penicillin and $100 \mathrm{mg} / \mathrm{ml}$ streptomycin in a humidified atmosphere with $5 \% \mathrm{CO}_{2}$ at $37^{\circ} \mathrm{C}$. The hTERT immortalized hTERT-BJ1 (BD Biosciences Clontech) ${ }^{54)}$ were grown in DMEM media supplemented with $10 \%$ fetal calf serum, 100 units/ml penicillin and $100 \mathrm{mg} / \mathrm{ml}$ streptomycin, $1 \mathrm{~mm}$ sodium pyruvate, and $4 \mathrm{~mm} l$-arginine in a humidified atmosphere with $5 \% \mathrm{CO}_{2}$ at $37^{\circ} \mathrm{C}$. Culture media were changed every $3 \mathrm{~d}$. To establish stable cell lines that the expression of hTERT could be monitored by a reporter system, a $c a$. $3.3 \mathrm{kbp}$ DNA fragment ranging from -3338 to $+1 \mathrm{bp}$ of the hTERT gene was subcloned upstream to a secreted alkaline phosphatase gene (SEAP) and transfected into H1299 or hTERT-BJ1 by electroporation. The stable clones were selected using G418. The stable clones derived from H1299 or hTERT-BJ1 were cultured using conditions that are similar to their parental cells.

Cytotoxicity Assay The tetrazolium reagent (MTT; 3-(4,5-di-methylthiazol)-2,5-diphenyltetrazolium bromide, USB) was designed to yield a colored formazan upon metabolic reduction by viable cells. ${ }^{55,56)}$ Approximately $2 \times 10^{3}$ cells were plated onto each well of a 96-well plate and incubated in $5 \% \mathrm{CO}_{2}$ at $37^{\circ} \mathrm{C}$ for $24 \mathrm{~h}$. To assess the in vitro cytotoxicity, each compound was dissolved in DMSO and prepared immediately before the experiments and was diluted into the complete medium before addition to cell cultures. Test compounds were then added to the culture medium for various designated concentrations. After $48 \mathrm{~h}$, an amount of $25 \mu \mathrm{l}$ of MTT was added to each well, and the samples were incubated at $37^{\circ} \mathrm{C}$ for $4 \mathrm{~h}$. A $100 \mu \mathrm{l} \mathrm{solu-}$ tion of lysis buffer containing $20 \%$ SDS and $50 \% \mathrm{~N}, \mathrm{~N}$-dimethylformamide was added to each well and incubated at $37^{\circ} \mathrm{C}$ for another $16 \mathrm{~h}$. The absorbency at $550 \mathrm{~nm}$ was measured using an ELISA reader.

Telomerase Assay The telomeric repeat amplification protocol (TRAP) is commonly used to evaluate telomerase activity in tissues or cell extracts and also to determine the inhibitory properties of small molecules against telomerase. A modified telomeric-repeat-amplification protocol (TRAP-G4) was utilized for G-quadruplex-induced telomerase activity assay. ${ }^{37)}$ Telomerase products were resolved by $10 \%$ polyacrylamide gel electrophoresis and visualized by staining with SYBER Green. As a source of telomerase, the total cell lysates derived from lung cancer cell line H1299 cells were used. Protein concentration of the lysates was assayed using Bio-Rad protein assay kit using BSA standards.

SEAP Assay ${ }^{57)}$ Secreted alkaline phosphatase was used as the reporter system to monitor the transcriptional activity of hTERT. Here, about $10^{4}$ cells each were grown in 96-well plates and incubated at $37^{\circ} \mathrm{C}$ for $24 \mathrm{~h}$ and changed with fresh media. Varying amounts of drugs were added and cells were incubated for another $24 \mathrm{~h}$. Culture media were collected and heated at $65^{\circ} \mathrm{C}$ for $10 \mathrm{~min}$ to inactivate heat-labile phosphatases. An equal amount of SEAP buffer ( $2 \mathrm{M}$ diethanolamine, $1 \mathrm{~mm} \mathrm{MgCl}_{2}$, and $20 \mathrm{~mm} l$-homoarginine) was added to the media and $p$-nitrophenyl phosphate was added to a final concentration of $12 \mathrm{~mm}$. Absorptions at $405 \mathrm{~nm}$ were taken, and the rate of absorption increase was determined.

Acknowledgements The present study was supported by National Science Council Grants NSC 94-2113-M-016-003, 95-2113-M-016-002-MY2, 94-2311-B-010-012 and 94-3112-B-010-020 and also by National Health Research Institute grant NHRI-EX95-9436SI. The authors are also indebted to Dr. K. K. Mayer (Universität Regensburg, Germany) for the mass spectrometry analytical determinations.

\section{References}

1) Dimri G. P., Lee X., Basile G., Acosta M., Scott G.., Roskelley C., Medrano E. E., Linskens M., Rubelj I., Pereira-Smith O., Peacocke M., Campisi J., Proc. Natl. Acad. Sci. U.S.A., 92, 9363-9367 (1995).

2) Morin G. B., Cell, 59, 521-529 (1989).
3) Zakian V. A., Science, 270, 1601-1607 (1995).

4) Allsopp R. C., Chang E., Kashefi-Aazam M., Rogaev E. I., Piatyszek M. A., Shay J. W., Harley C. B., Exp. Cell Res., 220, 194-200 (1995).

5) Ulaner G. A., Hu J. F., Vu T. H., Giudice L. C., Hoffman A. R., Cancer Res., 58, 4168-4172 (1998).

6) Meyerson M., Toxicol. Lett., 102-103, 41-45 (1998).

7) Neidle S., Kelland L. R., Anticancer Drug Des., 14, 341-347 (1999).

8) Feng J., Funk W. D., Wang S. S., Weinrich S. L., Avilion A. A., Chiu C. P., Adams R. R., Chang E., Allsopp R. C., Yu J., Le S., West M. D., Harley C. B., Andrew W. H., Greider C. W., Villeponteau B., Science, 269, 1236-1241 (1995).

9) Neidle S., Parkinson G., Nat. Rev. Drug Discov., 1, 383-393 (2002).

10) Shay J. W., Wright W. E., Cancer Cell, 2, 257-265 (2002).

11) Pennarun G., Granotier C., Gauthier L. R. Gomez D., Hoffschir F., Mandine E., Riou J. F., Mergny J. L., Mailliet P., Boussin F. D., Oncogene, 24, 2917-2928 (2005)

12) Burger A. M., Dai F., Schultes C. M., Reszka A. P., Moore M. J., Double J. A., Neidle S., Cancer Res., 65, 1489-1496 (2005).

13) Zee-Cheng R. K., Cheng C. C., J. Med. Chem., 21, $291-294$ (1978).

14) Cheng C. C., Zee-Cheng R. K., Prog. Med. Chem., 20, 83-118 (1983).

15) Zee-Cheng R. K., Mathew A. E., Xu P. L., Northcutt R. V., Cheng C. C., J. Med. Chem., 30, 1682-1686 (1987).

16) Maluf F. C., Spriggs D., Gynecol. Oncol., 85, 18-31 (2002).

17) Keppler M. D., Read M. A., Perry P. J., Trent J. O., Jenkins T. C., Reszka A. P., Neidle S., Fox K. R., Eur. J. Biochem., 263, 817-825 (1999).

18) Bosch R., Friederich U., Lutz W. K., Brocker E., Bachmann M., Schlatter C., Mutat. Res., 188, 161-168 (1987).

19) Li N., Ma Y., Yang C., Guo L., Yang X., Biophys. Chem., 116, 199 205 (2005).

20) Huang H. S., Chou C. L., Guo C. L., Yuan C. L., Lu Y. C., Shieh F. Y., Lin J. J., Bioorg. Med. Chem., 13, 1435-1444 (2005).

21) Neidle S., Read M. A., Biopolymers, 56, 195-208 (2000).

22) Perry P. J., Read M. A., Davies R. T., Gowan S. M., Reszka A. P., Wood A. A., Kelland L. R., Neidle S., J. Med. Chem., 42, 2679-2684 (1999).

23) Read M. A., Wood A. A., Harrison J. R., Gowan S. M., Kelland L. R., Dosanjh H. S., Neidle S., J. Med. Chem., 42, 4538-4546 (1999).

24) Mergny J. L., Helene C., Nat. Med., 4, 1366-1367 (1998).

25) Perry P. J., Gowan S. M., Reszka A. P., Polucci P., Jenkins T. C., Kelland L. R., Neidle S., J. Med. Chem., 41, 3253-3260 (1998).

26) Sun D., Thompson B., Cathers B. E., Salazar M., Kerwin S. M., Trent J. O., Jenkins T. C., Neidle S., Hurley L. H., J. Med. Chem., 40, 2113-2116 (1997).

27) Huang H. S., Chiou J. F., Fong Y., Hou C. C., Lu Y. C., Wang J. Y., Shih J. W., Pan Y. R., Lin J. J., J. Med. Chem., 46, 3300-3307 (2003).

28) Perry P. J., Reszka A. P., Wood A. A., Read M. A., Gowan S. M., Dosanjh H. S., Trent J. O., Jenkins T. C., Kelland L. R., Neidle S., J. Med. Chem., 41, 4873-4884 (1998).

29) Agbandje M., Jenkins T. C., McKenna R., Reszka A. P., Neidle S., J. Med. Chem., 35, 1418-1429 (1992).

30) Huang H. S., Chiu H. F., Lee A. L., Guo C. L., Yuan C. L., Bioorg. Med. Chem., 12, 6163-6170 (2004).

31) Huang H. S., Chiu H. F., Tao C. W., Chen I. B., Chem. Pharm. Bull., 54, 458-464 (2006).

32) Murdock K. C., Child R. G., Fabio P. F., Angier R. B., Wallace R. E., Durr F. E. Citarella R. V., J. Med. Chem., 22, 1024-1030 (1979).

33) Murdock K. C., Child R. G., Lin Y., Warren J. D., Fabio P. F., Lee V. J., Izzo P. T., Lang S., A. Jr., Angier R. B., Citarella R. V., Wallace R. E., Durr F. E., J. Med. Chem., 25, 505-518 (1982).

34) Cairns D., Michalitsi E., Jenkins T. C., Mackay S. P., Bioorg. Med Chem., 10, 803-807 (2002).

35) Palumbo M., Palu G., Gia O., Ferrazzi E., Gastaldi S., Antonello C., Meloni G. A., Anticancer Drug Des., 1, 337-346 (1987).

36) Venitt S., Crofton-Sleigh C., Agbandje M., Jenkins T. C., Neidle S., J. Med. Chem., 41, 3748-3752 (1998).

37) Gomez D., Mergny J. L., Riou J. F., Cancer Res., 62, 3365-3368 (2002).

38) Levine S., Gherson J., Int. J. Immunopharmacol., 8, 999-1007 (1986).

39) Read M., Harrison R. J., Romagnoli B., Tanious F. A., Gowan S. H., Reszka A. P., Wilson W. D., Kelland L. R., Neidle S., Proc. Natl. Acad. Sci. U.S.A., 98, 4844-4849 (2001). 
40) Perry P. J., Jenkins T. C., Expert Opin. Investig. Drugs, 8, 1981—2008 (1999).

41) Fisher G. R., Patterson L. H., J. Pharm. Pharmacol., 43, 65-68 (1991).

42) De Isabella P., Palumbo M., Sissi C., Capranico G., Carenini N., Menta, E., Oliva A., Spinelli S., Krapcho A. P., Giuliani F. C., Zunino F., Mol. Pharmacol., 48, 30-38 (1995).

43) Thielmann H. W., Popanda O., Gersbach H., Gilberg F., Carcinogenesis, 14, 2341-2351 (1993).

44) Fox E. J., Neurology, 63, S15-18 (2004).

45) Cheng C., Zee-Cheng R., "Progress in Medicinal Chemistry," Elsevier Science Publishers, New York, 1989, p. 83.

46) Huang H. S., Chiou J. F., Chiu H. F., Hwang J. M., Lin P. Y., Tao C. W., Yeh P. F., Jeng W. R., Chem. Pharm. Bull., 50, 1491-1494 (2002).

47) Huang H. S., Chiu H. F., Chiou J. F., Yeh P. F., Tao C. W., Jeng W. R., Arch. Pharm. (Weinheim), 335, 481-486 (2002).

48) Huang H. S., Hwang J. M., Jen Y. M., Lin J. J., Lee K. Y., Shi C. H., Hsu H. C., Chem. Pharm. Bull., 49, 969-973 (2001).
49) Huang H. S., Chiu H. F., Lu W. C., Yuan C. L., Chem. Pharm. Bull., 53, 1136-1139 (2005)

50) Anantha N. V., Azam M., Sheardy R. D., Biochemistry, 37, 27092714 (1998).

51) Hurley L. H., Wheelhouse R. T., Sun D., Kerwin S. M., Salazar M., Fedoroff O. Y., Han F. X., Han H., Izbicka E., Von Hoff D. D., Pharmacol. Ther, 85, 141-158 (2000).

52) Eom S. H., Wang J., Steitz T. A., Nature (London), 382, 278-281 (1996).

53) Doublie S., Ellenberger T., Curr. Opin. Struct. Biol., 8, 704-712 (1998).

54) Bodnar A. G., Ouellette M., Frolkis M., Holt S. E., Chiu C. P., Morin G. B., Harley C. B., Shay J. W., Lichtsteiner S., Wright W. E., Science, 279, 349-352 (1998).

55) Mosmann T., J. Immunol. Methods, 65, 55-63 (1983).

56) Denizot F., Lang R., J. Immunol. Methods, 89, 271-277 (1986).

57) Cullen B. R., Malim M. H., Methods Enzymol., 216, 362-368 (1992). 